\title{
Effect of section geometry on development of shrinkage- induced deformations in box girder bridges
}

\author{
Haidong Huang • Reyes Garcia $@$ • Maurizio Guadagnini $\cdot$ Kypros Pilakoutas
}

Received: 27 June 2017/ Accepted: 1 September 2017/Published online: 9 September 2017

(C) The Author(s) 2017. This article is an open access publication

\begin{abstract}
Non-uniform shrinkage strains can lead to significant additional deflections in large box girder bridges, leading to serviceability problems. This article examines experimentally and analytically the effect of different cross-section geometries on the shrinkage camber of bridge box girders. Small-scale beams were tested to determine the development of shrinkage strains across the beams of depth. Parameters investigated include cross section thickness, drying conditions, and type of concrete mix. Based on the experimental results, inverse analysis is utilised to obtain a surface factor and a hydro-shrinkage coefficient. In this study, such vales are used to determine, for the first time, shrinkage-induced bending deformations of long-span bridges using a hydro-mechanical approach. The results are then used to examine numerically the effect of different section geometries on the development of shrinkage camber. It is shown that the analytical predictions match the experimental results with an accuracy of $85 \%$. A further parametric study is carried out to investigate the effects of
\end{abstract}

H. Huang

Department of Bridge Engineering, Chongqing Jiao Tong University, 66 Xuefu Street, Nan'an District,

Chongqing 400074, China

R. Garcia $(\bowtie) \cdot$ M. Guadagnini · K. Pilakoutas Department of Civil and Structural Engineering, The University of Sheffield, Sir Frederick Mappin Building, Mappin Street, Sheffield S1 3JD, UK

e-mail: r.garcia@sheffield.ac.uk specimen geometry and ambient relative humidity. The hydro-mechanical approach is further validated using shrinkage field data from the $230 \mathrm{~m}$ two-span box girder Yiju River Bridge (China). The approach proposed in this study is expected to contribute towards improving the predictions of the long term behaviour of box girder bridges and towards better bridge management.

Keywords Shrinkage $\cdot$ Size effects $\cdot$ Hydromechanical coupling $\cdot$ Box girder bridges . Deflections · Camber

\section{Introduction}

Box girders are widely used in the design and construction of prestressed concrete (PC) bridges due to their structural efficiency and cost-effectiveness. However, in recent years numerous of such bridges experienced excessive vertical deflections at mid-span, affecting significantly serviceability and aesthetics [1]. Previous research has attributed these large deflections to additional curvatures produced by non-uniform shrinkage strain across the depth of concrete girders $[2,3]$. Changes in the sectional shape and size are also expected to contribute to the development of shrinkage camber as the drying rate is not uniform over the cross section. To date, 
however, the shrinkage camber caused by sectional shape has not been examined experimentally.

The process of drying shrinkage is caused by diffusion of moisture from the inside to the outer surface of concrete when this is exposed to a drying environment. The most effective way to mitigate the effect of shrinkage deformations is to prevent the loss of moisture and to protect the concrete from rapid drying [4]. However, the complete elimination of internal deformations is practically impossible. As a result, it is important to develop practical ways to account for shrinkage strains during construction as well as for structural assessment required for bridge management.

Current design guidelines include approximate analytical models to predict the long-term shrinkage behavior of concrete (e.g. ACI 209 [5] and Model Code 2010 (MC 2010) [6]). These models account for factors such as type of concrete, ambient relative humidity (RH), as well as cross section size and shape. In these models, the theoretical cross section thickness is defined by an average drying path length representing the entire cross section [3], which reflects the expectation that uniform drying shrinkage produces only axial shortening deformation but no deflection. While the above models are widely used in bridge design/analysis, they were proved unsuitable for calculating deflections of long span bridges with box girders [7, 8].

Different studies have investigated non-uniform shrinkage effects in box girder sections. Using the KB bridge (in Palau) as case study, Křístek [8] estimated the different shrinkage and creep effects of box girder bridges by assigning different shrinkage properties to each part of a whole box section, using different thicknesses for the web, top and bottom slabs. Křístek concluded that this approach can produce more accurate predictions than using the whole box section for calculating long-term deflections and stress redistributions. A more accurate 3D solid model of the KB bridge identified that the non-uniform distribution of drying shrinkage within the box girder section (due to the variation in thickness among different parts of the section) was one of the causes for excessive vertical deflections [2]. Malm and Sundquist [9] examined the shrinkage behaviour of the hollow box-girder Gröndal bridge (Sweden) using finite element (FE) analysis. The results showed that, after 2 years of service, nonuniform drying shrinkage accounted for $18 \%$ of the total bridge deflection. However, the above studies ignored the fact that shrinkage and creep depend on the section thickness, which varies across the cross section and along the bridge. Therefore, to accurately simulate the behaviour of an entire bridge, a large number of different geometries and shrinkage and creep models are needed, which makes the analysis computationally demanding and time-consuming.

To address the above drawbacks, more precise (yet complex) moisture diffusion analyses have been used to evaluate differential drying shrinkage deformations. For instance, numerical methods based on finite differences have been adopted to analyse the effect of internal RH changes over the cross section depth, along with a shrinkage coefficient that relates the internal RH and shrinkage deformations [10-13]. Multi-field models that consider thermal-diffusion coupling effects were also used to assess the thermalshrinkage stress of large concrete structures [14-17]. Theoretically, the above mentioned approach based on hydro-mechanical analysis can be used to predict the time dependent deformations of box girders with complex cross sections. However, the input parameters in the diffusion model (e.g. diffusion coefficient, surface factor and hydro-shrinkage coefficient) affect the accuracy of the predictions. The moisture diffusion coefficient depends on the internal RH of concrete and reflects the moisture transfer during drying. Existing guidelines (e.g. Model Code 90 [18] and MC2010 [6]) suggest analytical expressions to compute the moisture diffusion coefficient. The surface factor (also called transport coefficient or convection coefficient) represents the velocity of internal moisture that evaporates through the concrete surface to the environment. The surface factor depends on the w/c ratio and the moisture gradient and, consequently, its value should be determined on a case by case basis. Previous research also found that surface factor values had a large scatter [19, 20]. The hydro-shrinkage coefficient (also called contraction coefficient and shrinkage coefficient) is the coupling condition between free shrinkage strain and varying moisture. Typical values of hydro-shrinkage coefficient range from 1.2 to $3.0 \mathrm{~mm} / \mathrm{m}$ [21, 22]. The surface factor and the hydro-shrinkage coefficient can be calibrated using a combination of tests results and parametric studies.

This article examines experimental and analytically the effect of cross-section geometry on the development of shrinkage deformation of box girders of 
bridges. Section 2 of this study discusses methods for calculating shrinkage camber. Subsequently, Sect. 3 presents and discusses results of an experimental programme aimed to obtain surface factors and hydroshrinkage coefficients from beam specimens. Section 4 proposes to use, for the first time, a hydromechanical coupling model to simulate the shrinkageinduced bending deformation of the tested beams. The model is further validated by predicting the deflections of an actual case study bridge (Sect. 5). Concluding remarks of this study are given in Sect. 6. This article aims to contribute towards the development of more accurate models to assess the overall deflection of box girder bridges so as to improve the performance, serviceability and economic viability of structures.

\section{Calculation of shrinkage camber and moisture diffusion}

\subsection{Shrinkage camber}

Non-uniform shrinkage over the beam depth can produce both shortening deformation and bending deformations along the beam. By assuming that every small element in the cross section can deform freely, the free shrinkage strain $\varepsilon_{\mathrm{sh}}$ at an element located at $(x$, $y$ ) from the onset of shrinkage strain can be calculated as follows:

$\varepsilon_{\mathrm{sh}}(x, y)=\beta(1-\Delta H(x, y))$

where $\beta$ is the hydro-shrinkage coefficient; and $\Delta H$ is the change of pore humidity at $(x, y)$.

If a plane strain distribution along the beam depth is assumed, the shrinkage curvature $\psi_{\mathrm{sh}}$ can be obtained:

$\psi_{\mathrm{sh}}\left(t_{\mathrm{s}}, t\right)=\frac{1}{I} \int_{t_{\mathrm{s}}}^{t} \iint_{A} \Delta \varepsilon_{\mathrm{sh}}\left(y-y_{\mathrm{c}}\right) \mathrm{d} A \mathrm{~d} t$

where $t_{\mathrm{s}}$ and $t$ are the time at the onset of shrinkage strain and the analysis time, respectively; $y-y_{\mathrm{c}}$ is the distance from the element to the neutral axis of the whole section; $I$ is the moment of inertia of the whole section; and $A$ is the area of the whole section.

Likewise, the longitudinal average strain $\bar{\varepsilon}_{\mathrm{sh}}$ is:

$\bar{\varepsilon}_{\mathrm{sh}}\left(t_{\mathrm{s}}, t\right)=\frac{1}{A} \int_{t_{\mathrm{s}}}^{t} \iint_{A} \Delta \varepsilon_{\mathrm{sh}} \mathrm{d} A \mathrm{~d} t$ where all the variables are as defined before. It should be noted that the internal reinforcement restrains the development of shrinkage-induced deformations, and that this can lead to stress and strain redistributions over the cross section's height. However, in current design practice, the restrain of reinforcement is usually neglected in typical prestressed bridges with relative low reinforcement ratios. As a result, such restraining effect are neglected in subsequent analysis of the case study bridge presented later in this article.

\subsection{Moisture diffusion over cross section}

The time-dependent shrinkage of concrete consists of four main sources, including drying, autogenous, plastic and carbonation shrinkage. Water in concrete is consumed during hydration, and therefore the internal moisture decreases and affects the humidity diffusion process. As a result, autogenous shrinkage is significant in high-strength concrete during the early ages. According to Fick's second law, the diffusion equation with the effect of self-desiccation [23] can be expressed as:

$$
\left\{\begin{array}{l}
\frac{\partial H}{\partial t}=\nabla[D(H) \nabla H]+\frac{\partial H_{a}}{\partial t} \\
H(x, y)=H_{0}(x, y) \\
\left.D(H)\left(\frac{\partial H}{\partial n}\right)\right|_{S}=f\left(H_{\mathrm{en}}-H_{S}\right)
\end{array}\right.
$$

where $H$ is the pore humidity; $D(H)$ is the moisture diffusion coefficient; $\frac{\partial H_{a}}{\partial t}$ is the change rate of internal humidity due to self-desiccation; $H_{0}(x, y)$ is the initial condition function which denotes the initial internal humidity distribution at an element located at $(x, y) ; f$ is the surface factor; $H_{\mathrm{en}}$ is the environmental humidity; and $H_{\mathrm{s}}$ is the relative humidity on the exposed face $S$.

Equation (4) can be solved using finite difference methods that solve time-dependent nonlinear diffusion problems [24]. Accordingly, the FE governing equation in nonlinear diffusion analysis is [25]:

$[D]\{H\}+[C]\{\dot{H}\}=\{R\}$

where $[D]$ is the element humidity diffusion matrix; $[C]$ is the element humidity capacity matrix; and $[R]$ is the element boundary humidity flux. By using Euler backward implicit time integration and full Newton- 
Raphson iteration methods, the nonlinear transient equation can be rewritten as:

$$
\begin{aligned}
& { }_{t+\Delta t}^{i-1}[D]^{i}\{\Delta H\}+[C]_{t+\Delta t}^{i}[\dot{H}] \\
& \quad={ }_{t+\Delta t}\{R\}-{ }_{t+\Delta t}^{i-1}[D]_{t+\Delta t}^{i-1}[H]
\end{aligned}
$$

where $\Delta t$ is the time step; $i$ is the iteration number; and $\{\Delta H\}$ is the element humidity variation matrix from $t$ to $\Delta t$. According to the Euler backward difference method, ${ }_{i+\Delta t}^{i}\{\dot{H}\}$ can be expressed as:

${ }_{t+\Delta t}^{i}\{\dot{H}\}=\frac{{ }_{i-1}^{i-\Delta t}\{H\}+{ }^{i}\{\Delta H\}-{ }_{t}\{H\}}{\Delta t}$

The hydro-shrinkage coefficient $\beta$ links the moisture diffusion model and the structural shrinkage model described in Sect. 2.1. The time-dependent internal humidity distribution can be determined using Eqs. (5)-(7), whereas the shrinkage strain and curvature can be calculated using Eqs. (1)-(3). In this study, ADINA $^{\circledR}$ [26] software is used to simulate the drying process in concrete. The decrease of internal humidity due to self-desiccation is modelled by the timedependent uniform drying process, as shown later in Sect. 4.1.

In summary, to determine the development of shrinkage-induced deformations using the hydro-mechanical approach described in the previous sections, the following main assumptions and calculation steps are necessary:

1. Calibrate the surface factor $f$ and the hydroshrinkage coefficient $\beta$ using inverse analyses;

2. Calculate the time-dependent internal humidity distribution assuming that only drying and selfdesiccation occur; and

3. Assume a plane strain distribution along the beam depth and determine both shortening deformation and bending deformations along the beam using section analysis.

\section{Experimental programme}

\subsection{Test specimens and exposure conditions}

Four non-symmetric I cross section beams (group I) were produced and tested to examine the camber due to non-uniform shrinkage. The beams were cast sideways to eliminate differences in concrete properties along the height of the beam. The simplified scaled-down geometry of the short I beams replicated approximately half of a box girder section, as shown in Fig. 1. The beams had a total depth of $300 \mathrm{~mm}$, a total length of $500 \mathrm{~mm}$ and a web thickness of $50 \mathrm{~mm}$, as shown in Fig. 1. The thicknesses of the top and bottom slabs (flanges) were 50 and $100 \mathrm{~mm}$, respectively. For comparison, four control concrete prisms (specimens $\mathrm{B}$ and BS) of $100 \times 100 \times 450 \mathrm{~mm}$ were also cast. No reinforcement was used in the beams and prisms.

The I beam specimens were subjected to different exposure conditions to promote concrete drying shrinkage. To amplify the effect of differential shrinkage, the surfaces of the web and bottom slab of two specimens (IP-1 and IP-2) were epoxy coated to prevent drying, whereas two beam counterparts (I-1 and I-2) were fully exposed to the environment. Two prisms (BS) were fully epoxy coated on all surfaces, whereas two prisms (B) had only one surface exposed to the environment. Table 1 summarises the main characteristics of the tested specimens and their corresponding the mean concrete compressive strength $f_{\mathrm{c}}$.

\subsection{Material properties}

The I beams and prisms were cast using two batches of normal-strength concrete (mixes C1 and C2) typical of bridge construction in China. To investigate the effect of water-cement (w/c) ratio on drying and autogenous shrinkage, w/c ratios of 0.37 and 0.40 were selected for mixes $\mathrm{C} 1$ and $\mathrm{C} 2$, respectively. The following proportions were used for mix $\mathrm{C} 1$ : cement $=460 \mathrm{~kg} / \mathrm{m}^{3}$, gravel $=1270 \mathrm{~kg} / \mathrm{m}^{3}$, sand $=520 \mathrm{~kg} / \mathrm{m}^{3}$, whereas for $\operatorname{mix} \quad \mathrm{C} 2$ : cement $=410 \mathrm{~kg} / \mathrm{m}^{3}, \quad$ gravel $=$ $1275 \mathrm{~kg} / \mathrm{m}^{3}$, sand $=545 \mathrm{~kg} / \mathrm{m}^{3}$. For each batch, $f_{\mathrm{c}}$

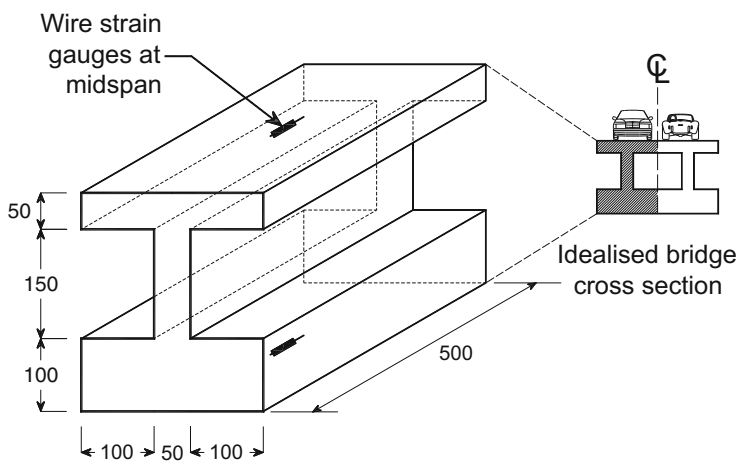

Fig. 1 General geometry of I beam (units: mm) 
Table 1 Main characteristics of tested specimens

\begin{tabular}{llll}
\hline ID & Mix & $f_{\mathrm{c}}, \mathrm{MPa}$ & Surface condition \\
\hline I-1 & $\mathrm{C} 1$ & 62.6 & Un-sealed I beam \\
IP-1 & $\mathrm{C} 1$ & 62.6 & Partially sealed I beam \\
I-2 & $\mathrm{C} 2$ & 54.5 & Un-sealed I beam \\
IP-2 & C2 & 54.5 & Partially sealed I beam \\
B-1 & C1 & 62.6 & Un-sealed rectangle specimen \\
BS-1 & C1 & 62.6 & Sealed rectangle specimen \\
B-2 & C2 & 54.5 & Un-sealed rectangle specimen \\
BS-2 & C2 & 54.5 & Sealed rectangle specimen \\
\hline
\end{tabular}

was obtained from concrete cubes tested at 28 days according to the Chinese JTG D60 bridge design code [27].

All specimens were moist-cured for 3 days following casting, after which the epoxy coating was applied onto the faces of the selected specimens. During testing, all specimens were kept in standard laboratory conditions. It should be noted that the tested beams have the same exposure conditions on the inner and outer faces of the simulated cross section. This is because, in actual bridge construction practice, the inner parts of the box sections are also exposed to the environment during the construction period of the cantilever segments (which can last for several months or years).

The I beams were rotated $90^{\circ}$ and simply supported on two steel rods to ensure that only free deformations occurred during the test. To measure the development of strain during drying, two vibrating wire strain gauges were installed along the centerline of the beams: one at the top slab and one beneath the bottom slab, as shown in Fig. 1. The strain gauges had a measurement range of $\pm 1500 \mu \varepsilon$ and an accuracy of $1 \mu \varepsilon$. The prisms were also supported on two steel rods and monitored by vibrating wire strain gauges. Measurements were read every day during the first week of testing. The beams and prims were monitored for a period of 115 days.

Figure $2 \mathrm{a}-\mathrm{b}$ show the evolution of shrinkage strains measured at the top (Top test data points) and bottom (Bot test data points) of the un-sealed specimens I-1 and I-2. As expected, the shrinkage strains were different at these locations, thus confirming that both axial shortening and shrinkage bending occurred during the tests. The difference between the measured data from top and bottom strain gauges (Top-Bot test) indicates the magnitude of the camber deformation, which results in additional bending deformations. The results indicate that during the first 58 days, the shrinkage strain on the top developed faster than that on the bottom, while the bending deformation increased. However, after 58 days, the camber decreased after reaching a peak value. These results were expected since, at the initial stages of the test, the development of drying shrinkage at the (thinner) top slab was faster than at the bottom slab. Consequently, an increasing upward camber deformation occurred over time but only up to a peak point. After this, drying shrinkage at the top slab developed more slowly than at the bottom slab because the majority of internal moisture in the former has been consumed by convection. The Top-Bot curve decreased with time, thus leading to a downward camber deformation.

Figure $2 \mathrm{c}-\mathrm{d}$ also show the evolution of shrinkage strains at the top and bottom of the sealed specimens IP-1 and IP-2, respectively. As expected, the difference between shrinkage strains on the top and bottom slabs is up to $55 \%$ higher than those of the corresponding un-sealed specimens (shown in Fig. 2a-b). However, shrinkage strains were still measured on the sealed surface of the specimens. This can be attributed to autogenous shrinkage but also to restraining effects of the sealed flange.

\section{Numerical analysis}

Based on the experimental results from Sect. 3, this section presents an inverse analysis performed to obtain the surface factor and the hydro-shrinkage coefficient. A parametric analysis is then carried out to examine the influence of specimen geometry and ambient RH on the shrinkage behaviour of the tested beams. It should be mentioned that solar radiation can significantly affect the long term drying process in actual concrete bridges. However, to simulate actual environmental conditions of a bridge, a more complex hydro-thermo-mechanical model would be needed to couple the effect of moisture, temperature and deformation fields, thus resulting in very demanding computational analyses. As a result, current guidelines use "average" RH and environmental temperature, which are also adopted in the calculations of this study. 


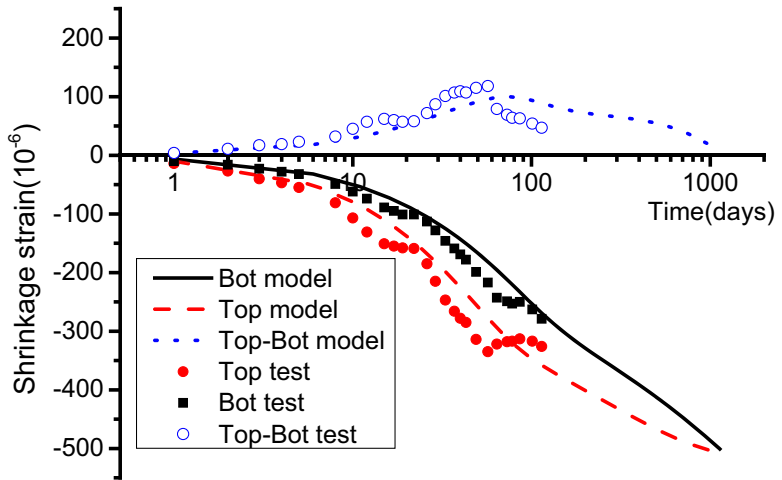

(a)

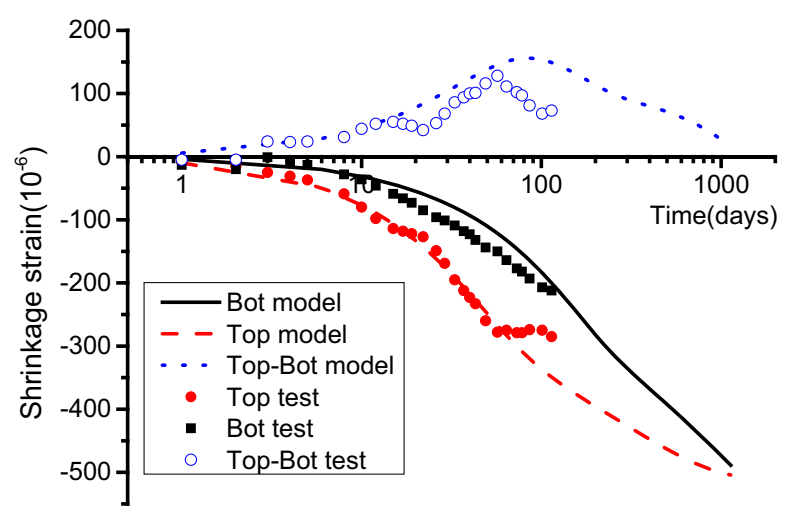

(c)

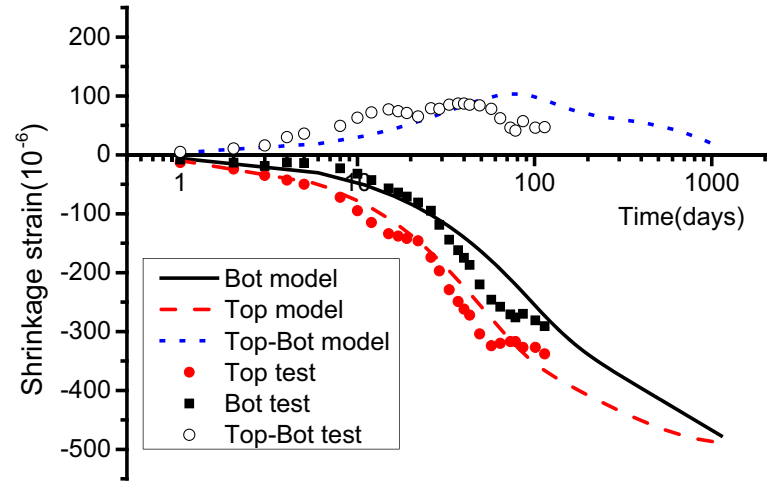

(b)

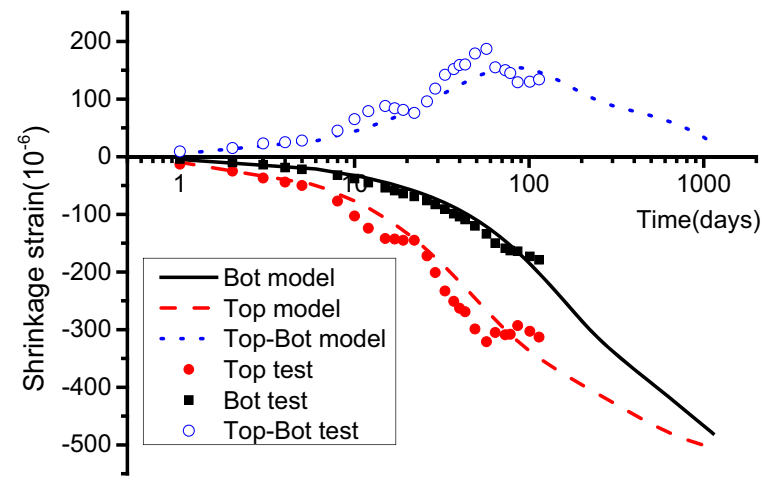

(d)

Fig. 2 Calculated shrinkage values versus experimental shrinkage values of I beams. a I-1, b I-2, c IP-1, d IP-2

\subsection{Basic parameters for modelling}

To determine suitable parameters for a hydro-mechanical model, a moisture diffusion analysis is first performed. This study adopts the approach suggested by the recent MC2010 [6], where the moisture diffusion coefficient $D(H)$ is calculated as:

$D(H)=D_{1}\left(\alpha+\frac{1-\alpha}{1+\left(\frac{1-H}{1-H_{c}}\right)^{n}}\right)$

where $H$ is the relative pore humidity; $D_{1}$ is the maximum of $D(H)$ for $H=1.0\left(D_{1}=1 \times 10^{-8}\left[\mathrm{~m}^{2} /\right.\right.$ $\mathrm{s}] / f_{\mathrm{ck}}, f_{\mathrm{ck}}=$ characteristic concrete strength); and $H_{\mathrm{c}}$ is the relative pore humidity at $D(H)=0.5 D_{1}$. According to MC2010, approximate values $\alpha=0.05$, $H_{\mathrm{c}}=0.80$ and $n=15$ can be used in the analysis.

A surface factor $f$ and a hydro-shrinkage coefficient are required for the moisture diffusion analysis.
Previous literature indicates that the surface factor $f$ depends on the water-cement ratio and the moisture gradient, and a wide range of values were suggested $[19,28]$. Likewise, the hydro-shrinkage coefficient was found to range between $1.1 \times 10^{-3}$ and $3.0 \times 10^{-3}[21,22]$.

In addition, free shrinkage strain is difficult to measure directly due to internal restraining effects. The FEA package ADINA ${ }^{\circledR}$ [26] was used to perform inverse analyses and estimate the surface factor and the hydro-shrinkage coefficient [19]. The results indicate that the best match is obtained for $f$ values of 0.3 and $0.5 \mathrm{~mm} /$ day for mixes $\mathrm{C} 1$ and $\mathrm{C} 2$, respectively (see Fig. 3). Likewise, the use of a hydro-shrinkage coefficient values of 0.0014-0.0015 led to good predictions for both concrete mixes. Consequently, these values are used in subsequent analyses.

At an early age, the internal moisture in concrete is consumed due to self-desiccation, thus leading to 


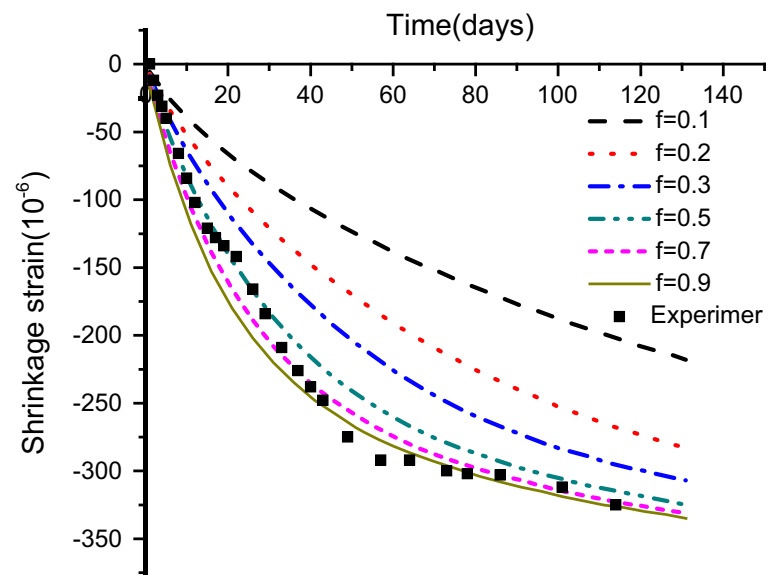

(a)

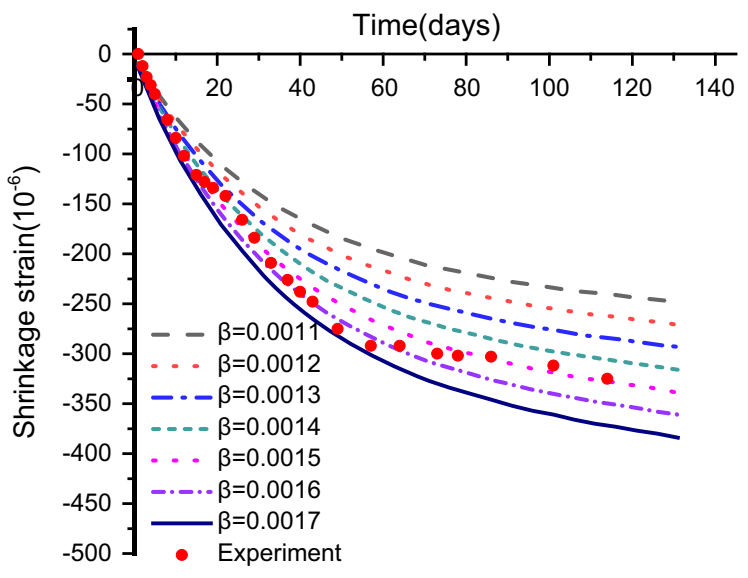

(b)

Fig. 3 Results of the parametric study on tested prisms cast with mix C2, units: $f(\mathrm{~mm} /$ day). a Surface factor $f$. b Hydro-shrinkage coefficient $\beta$

autogenous shrinkage. Since the experiments were conducted in a relatively short time, the effect of concrete self-desiccation needs to be accounted for in the analysis. As water is consumed by hydration, the internal RH decreases and interacts with the humidity diffusion process. The autogenous shrinkage depends on the water to binder ratio and on temperature. Whilst some predictive models have been previously proposed to compute autogenous shrinkage [23, 29], this study adopts the approach proposed in MC2010. Accordingly, the basic shrinkage $\varepsilon_{\mathrm{cbs}}$ is calculated as:

$\varepsilon_{\mathrm{cbs}}=\varepsilon_{\mathrm{cbs} 0} \beta_{\mathrm{bs}}(t)$

where $\varepsilon_{\text {cbs} 0}$ is the basic notional coefficient (which depends on the cement type and concrete compressive strength); and $\beta_{\mathrm{bs}}(t)$ is a time development function for basic shrinkage strain. The time development function for autogenous strain $\beta_{\mathrm{bs}}(t)$ can be computed as follows:

$\beta_{\mathrm{bs}}(t)=1-e^{-0.2 \sqrt{t}}$

By differentiating Eq. (10) with respect to $t$, Eq. (9) can be rewritten as:

$\dot{\varepsilon}_{\mathrm{cbs}}(t)=\frac{0.1 \varepsilon_{\mathrm{cbs} 0} \cdot e^{-0.2 \sqrt{t}}}{\sqrt{t}}$

Thus the change of internal humidity due to selfdesiccation can be calculated as: $\frac{\partial H_{a}}{\partial t}=\frac{0.1 \varepsilon_{\mathrm{cbs} 0} \cdot e^{-0.2 \sqrt{t}}}{\beta \sqrt{t}}$

where all the variables are as defined above.

To validate the autogenous shrinkage model, FE analyses were carried out to predict the behavior of prisms with sealed and unsealed surfaces. The surface factor $f$ was set to ' 0 ' in the analysis to simulate the effect of sealed surfaces, thus assuming that no moisture evaporated from the surface of the specimens and that only autogenous shrinkage occurred. Conversely, on the unsealed surfaces, $f$ was set to 0.3 and $0.5 \mathrm{~mm} /$ day for mixes $\mathrm{C} 1$ and $\mathrm{C} 2$, respectively. Figure 4 shows that the FE models predict the results of the tested prisms with good accuracy, in particular for the sealed specimens. The differences between the numerical predictions and the experimental results can be attributed to (a) the use of 'average' environmental conditions and temperature in the FE modelling, and (b) the intrinsic inhomogeneity of concrete structure, which led to different conditions along the prisms.

\subsection{FE modelling of hydro-mechanical behaviour}

As discussed in Sect. 2, the calculation of shrinkage deformations requires: (1) analysing the time-dependent moisture distribution over the cross section of the element, and (2) determining the shrinkage camber and resultant deformation through section analysis. In this study, the hydro-mechanical behaviour of the I 


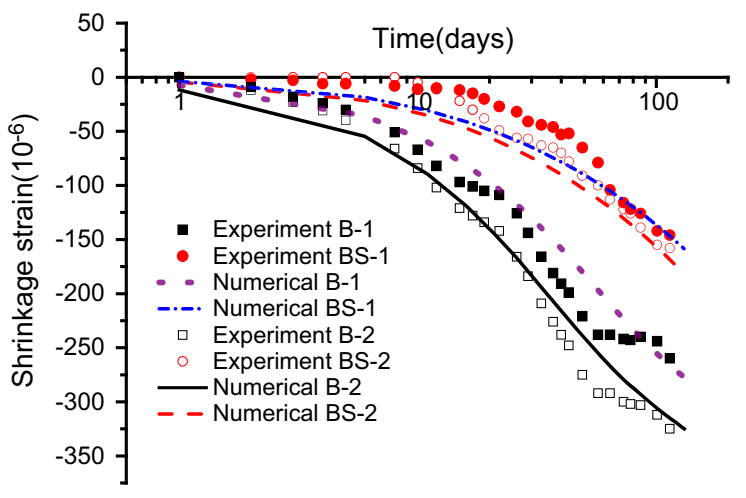

Fig. 4 Comparison of time dependent shrinkage of prisms with sealed and unsealed surfaces

beams was simulated using the diffusion model developed in Sects. 2 and 4, and a mechanical model (fibre-based section analysis [30]). These two models are linked by the hydro-shrinkage coefficient $\beta$ (see Eqs. 1, 4 and 12). 2D diffusion elements were adopted to calculate the internal distribution of $\mathrm{RH}$, whereas fibre elements were used to calculate time-dependent deformations. Both diffusion and mechanical models were discretised using quadrilateral elements with the same mesh size. The analyses to calculate the internal distribution of RH were performed using the general FEA package ADINA ${ }^{\circledR}$ [26], while the section analyses were carried out using routines programmed in Matlab $^{\circledR}$ software [31]. Based on the RH measured in the laboratory, a constant ambient $\mathrm{RH}=70 \%$ was used for the exposed surface in the diffusion model. The time-dependent internal RH due to self-desiccation was also considered in the FE modelling.

\subsection{Numerical results and discussion}

Figure $2 \mathrm{a}-\mathrm{d}$ compare the FE predictions with the experimental results of the I beams. The figures indicate that the FE predictions are in close agreement with the experimental results. The differences between the predictions and the test data can be attributed to the variation of environmental conditions (RH) and temperature during the tests, which cannot be captured by the FE models. This is confirmed by the smaller difference obtained between predictions and test results for the unsealed surface conditions (see Fig. 2b) when compared to partially sealed surface conditions (Fig. 2c). These results confirm that it is possible to develop appropriate numerical models to predict the shrinkage behaviour of the I beams with an acceptable accuracy. The results also indicate that the calibrated models can be used to perform further parametric analyses on the I beams. As expected, as the RH stabilises through the section, the difference in shrinkage between Top and Bottom slabs reduces, consequently reducing the shrinkage camber.

The experimental and FE results presented in Fig. 2a-d confirm that the cross section shape can lead to shrinkage camber and that it influences the development of shrinkage-induced deformations at different depths of the specimen. The results also indicate that the numerical approach adopted in this study can predict the shrinkage camber and shrinkage strain of the tested specimens with good accuracy. However, due to the limited number of specimens tested in this study, the influence of different cross section geometry and ambient $\mathrm{RH}$ on shrinkage camber was not examined. These effects are examined in the following section, which presents the results of a parametric study that was carried out to analyse the shrinkage camber of I beams with different cross sections and ambient RH.

\subsection{Parametric analysis using FE models}

\subsubsection{Influence of section depth}

To determine how the section depth influences shrinkage camber (expressed as curvature), the height of the web was scaled up 2-5 times. This led to web depths of 150, 300, 450, 600 and $750 \mathrm{~mm}$. The rest of the section dimensions were kept the same. The results in Fig. 5 show that the maximum value of shrinkage camber decreases as the height of the web increases. However, as the web thickness was the same, all peak values of camber are observed at around 30-40 days.

\subsubsection{Influence of size}

Figure 6 compares results of shrinkage camber for different section sizes. In this case, the original section was scaled up geometrically by factors of 2-5 times, thus leading to sections of (flange width $\times$ total depth) $250 \times 300, \quad 500 \times 600, \quad 750 \times 900$, $1000 \times 1200$ and $1250 \times 1500 \mathrm{~mm}$. The results indicate that size affects both the maximum value of shrinkage camber and the time at which it is achieved. For example, the change in scale factor from 1 to 5 


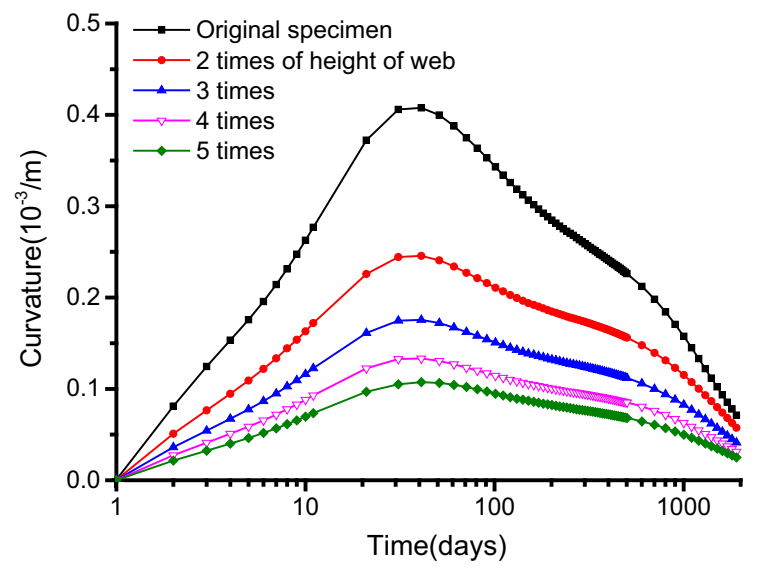

Fig. 5 Shrinkage camber with different web depth

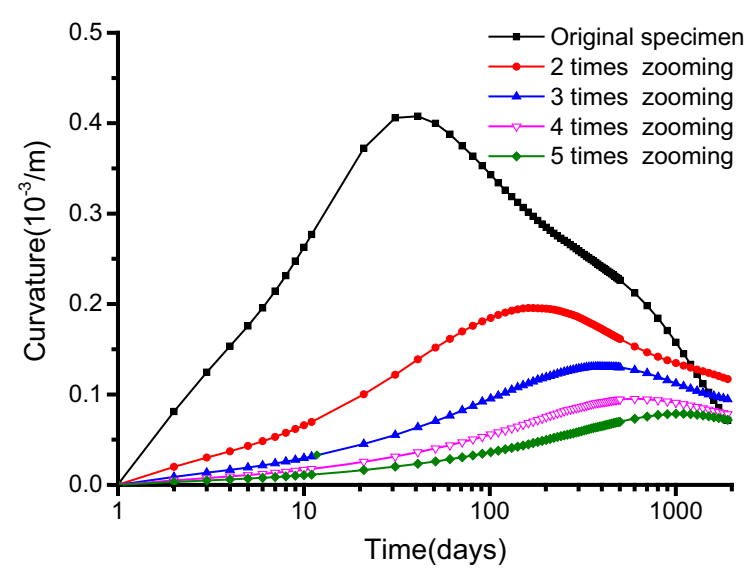

Fig. 6 Shrinkage camber with different section size

reduced the maximum camber from 0.40 to $0.05 / \mathrm{mm}$, while the time difference between peak camber was approximately 950 days.

\subsubsection{Influence of ambient humidity}

Figure 7 compares the response of the original model subjected to environmental $\mathrm{RH}$ varying from 40 to $80 \%$. The results indicate that, as the RH increases, the maximum value of the shrinkage camber decreases from $0.95 / \mathrm{mm} \quad(\mathrm{RH}=40 \%) \quad$ to $\quad 0.32 / \mathrm{mm}$ $(\mathrm{RH}=80 \%)$. It is also shown that the higher the $\mathrm{RH}$, the earlier the camber reduces and tends to zero. Such trend is attributed to the internal moisture balancing with the external ambient $\mathrm{RH}$.

\section{Case study validation}

\subsection{Description of the bridge}

The Yiju River Bridge at Chongqing, China (see Fig. 8) is selected as a case study to validate the hydromechanical FE approach proposed in this study. The two-span prestressed concrete box girder bridge was segmentally constructed over the Yiju River in 2016. The left and right spans of the bridge are $115 \mathrm{~m}$ long each, whereas the height of the main hollow boxsection pier is $85.8 \mathrm{~m}$. The $0.8 \mathrm{~m}$ thick main pier has transversal and longitudinal dimensions of $8.0 \mathrm{~m}$ and $9.0 \mathrm{~m}$, respectively. The $23 \times 17 \times 4.5 \mathrm{~m}$ solid pile cap is supported by 12 concrete piles of $3 \mathrm{~m}$ diameter.

The cross section consists of a single box girder with an $11.0 \mathrm{~m}$ wide cantilever slab. The total girder depth reduces from $14.98 \mathrm{~m}$ at the main pier (at section "A" in Fig. 8) to $4.5 \mathrm{~m}$ at the closure segment (at section "C" in Fig. 8). Likewise, the thickness of the bottom slab and web vary along the bridge. Three diaphragms are located within the box girder at all supports. The superstructure was built using a cast-inplace cantilevered system using 52 segments of different length (2, 3, 4, 4.8 and $5 \mathrm{~m})$. These segments were presstressed using two sets of tendons: 18 tendons of $15.2 \mathrm{~mm}$ diameter (in the top slab) and 23 tendons of $15.2 \mathrm{~mm}$ diameter (in the bottom slab), with initial forces of 3375 and $4312 \mathrm{kN}$, respectively. The total construction time of the superstructure was 330 days.

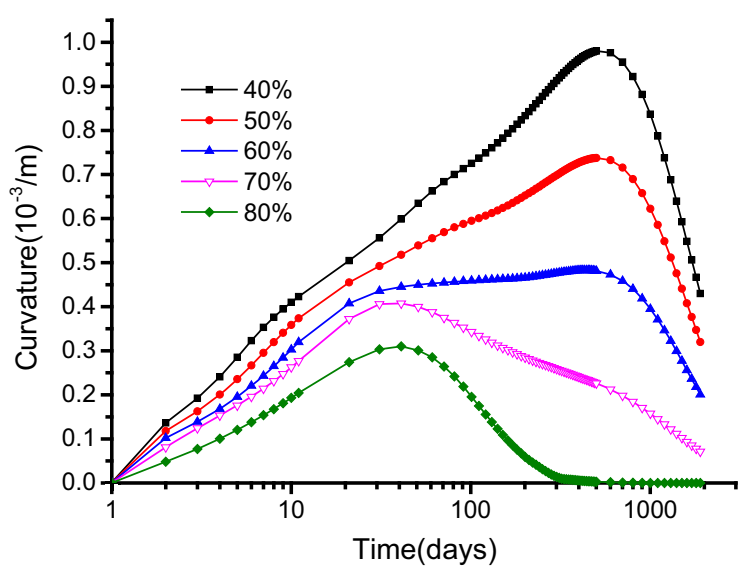

Fig. 7 Shrinkage camber with different ambient relative humidity 


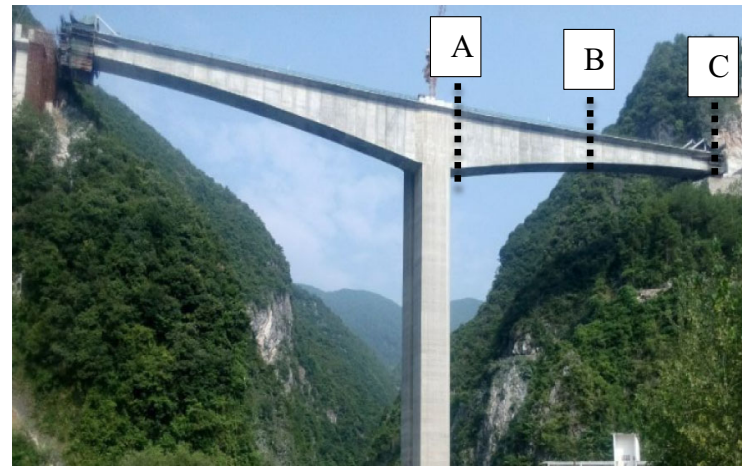

Fig. 8 General view of the Yiju River bridge and location of sections "A", "B" and "C" along the bridge span

The RH inside the top slab of the box girder section was measured using a digital sensor with $\mathrm{RH}$ and temperature accuracies of $\pm 2 \%$ and $\pm 0.3{ }^{\circ} \mathrm{C}$, respectively. Three digital $\mathrm{RH}$ sensors were installed on the top slab of the mid-span section " $B$ " at depths of 0,30 and $100 \mathrm{~mm}$ from the top slab surface. The sensors were fixed to steel rebars, which in turn were welded to the girder's reinforcing cage. PVC tubes of $30 \mathrm{~mm}$ diameter protected the sensors during concrete casting. The data was collected using DC powered equipment.

\subsection{FE validation and results}

A total of 26 sectional models were used to simulate the 52 cantilever segments of the bridge in ADINA ${ }^{\circledR}$ software. Due to symmetry, only half of the bridge's cross section was modelled to reduce computational time. In the diffusion analysis, an average measured environment humidity $H_{\mathrm{e}}=0.70$ was applied on the box girder surfaces as the convection boundary. The elastic modulus $\left(E=3.45 \times 10^{4} \mathrm{MPa}\right)$ was obtained from tests on cubes, whereas the surface factor $(f=0.0005 \mathrm{~m} /$ day $)$ and the hydro-shrinkage coefficient $\left(\beta=1.58 \times 10^{-3}\right)$ were determined from a parametric analysis based on MC2010 and measured data.

The digital sensor on the box girder surface recorded ambient $\mathrm{RH}$ ranging from 51 to $100 \%$, while the ambient temperature varied from 20 to $40{ }^{\circ} \mathrm{C}$ during the measuring period (27 days). The short measuring period was due to the practical and financial constraints of the project. Figure 9a shows that the internal RH at depths of 30 and $100 \mathrm{~mm}$ decrease over time due to self-desiccation and drying of concrete. The measured internal $\mathrm{RH}$ at $30 \mathrm{~mm}$ depth decreases from 100 to $87 \%$ after 27 days. As expected, the $\mathrm{RH}$ at $30 \mathrm{~mm}$ is lower than that at $100 \mathrm{~mm}$ depth. The field data also show that the internal RH is significantly affected by the variation of ambient $\mathrm{RH}$ and temperature, as shown by the large scatter of data at $30 \mathrm{~mm}$ depth. Figure $9 \mathrm{a}$ also shows that the sectional diffusion analysis over the cross section of the bridge captures well the trend of the internal $\mathrm{RH}$ at both depths. Since the FE models use an average ambient $\mathrm{RH}$, the calculated time-dependent $\mathrm{RH}$ curves are much smoother than the measured data.

Figure $9 \mathrm{~b}$ compares the calculated distribution of the internal RH at ages of 30, 2000 and 10,000 days (approximately 0, 5 and 27 years, respectively). It is shown that, within the first 30 days, the drying depth from the exposed surface is $50-100 \mathrm{~mm}$ and the internal RH at the center of the slab and web varies less than $1 \%$. However, after 2000 days, the drying depth increases and some parts of the box section (e.g. thin top slabs) dry at a faster rate than the web. The internal $\mathrm{RH}$ of the thicker sections of the top and bottom slabs remains relatively high (up to 95\%) even after 10,000 days, thus leading to a low shrinkage strain.

To study the long term shrinkage camber and shrinkage strain, the Yiju River bridge was divided into 26 sections in ADINA $^{\circledR}$. The sections had the same drying boundary conditions used in the previous analysis. The restrain of the bridge supports was considered by assigning suitable structural boundaries in the analysis of time-dependent deflection. As this study examines long periods of time, an average RH of $70 \%$ and an average temperature of $20^{\circ} \mathrm{C}$ were adopted in the FE models, which are deemed representative of future conditions at the Yiju River bridge. Dead load was neglected in the analysis. Figure 10a compares the development of shrinkage camber over time at sections "A", "B" and "C", which are representative of the bridge's sections at the pier, midspan and closure segments. The results confirm that shrinkage camber occurs at all sections due to differential drying across the box section, and that the magnitude of shrinkage camber depends on the size of the section. For example, the bottom slab thickness of section " $\mathrm{A}$ " is $1.92 \mathrm{~m}$, or 2.5 times the slab thickness of section " $\mathrm{B}$ ", and the maximum shrinkage camber at "A" is $6 \times 10^{-6} / \mathrm{m}$, i.e. 1.5 times the value at " $\mathrm{B}$ " $\left(4 \times 10^{-6} / \mathrm{m}\right)$. Figure 10 a also shows that the 
Fig. 9 Comparison of measured and calculated internal RH at section "B" of Yiju River Bridge. a Internal RH development. b Calculated $\mathrm{RH}$ distribution at Section "B"

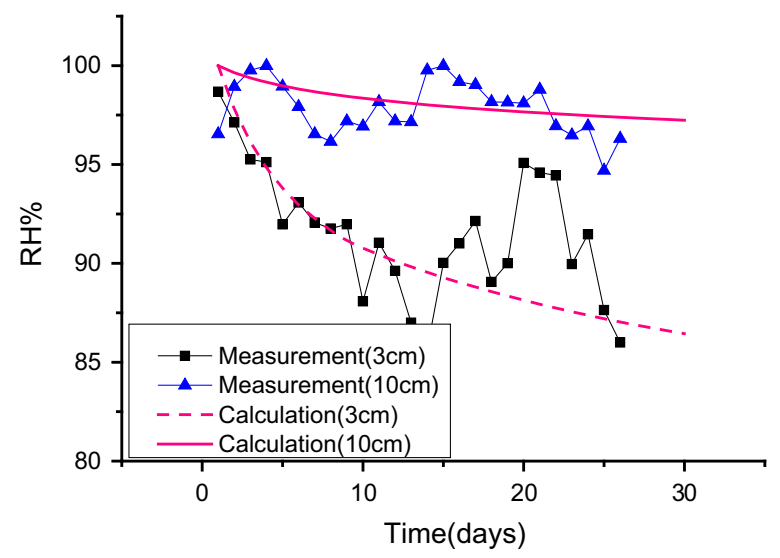

(a)

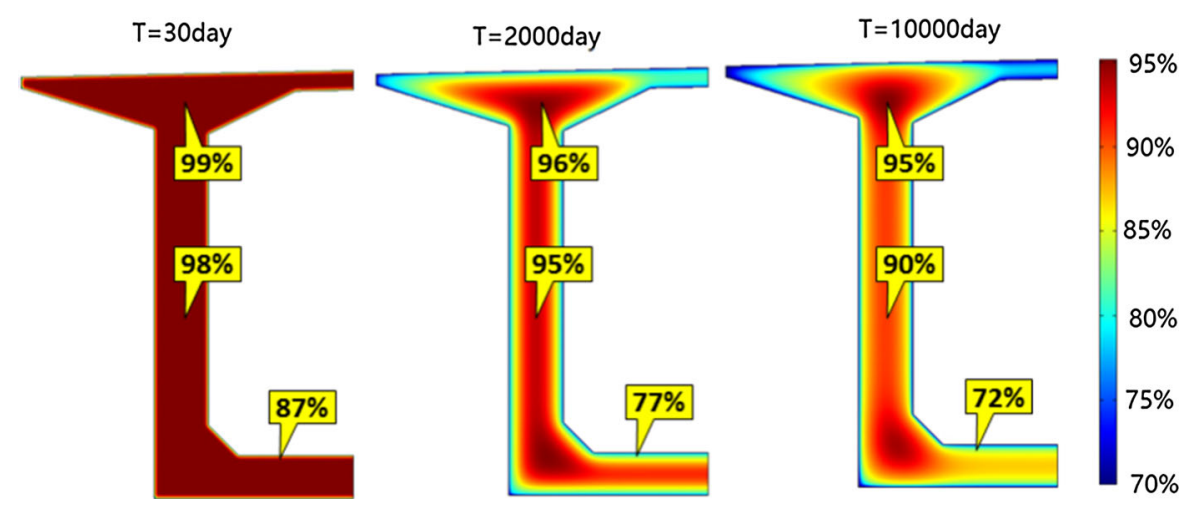

(b)

evolution of shrinkage camber at "A" lags behind that at "B". Unlike sections " $A$ " and "B", a negative shrinkage camber is observed at " $\mathrm{C}$ " as at this section the top slab is thicker than the bottom slab. The minimum shrinkage camber is $-10 \times 10^{-6} / \mathrm{m}$ at 2000 days and the residual shrinkage camber is $-8 \times 10^{-6} / \mathrm{m}$ at 10,000 days.

Figure $10 \mathrm{~b}$ compares the longitudinal average axial shrinkage strain at sections "A", "B" and "C" calculated according to Eq. 3 and MC 2010. The results in the figure were obtained using the nominal thickness given by MC 2010, which is defined as two times the ratio of the cross-sectional area to the perimeter of the structural member in contact with the atmosphere. This led to nominal thicknesses of 1181 , 795 and $497 \mathrm{~mm}$ at sections "A", "B" and "C", respectively. It should be noted that the hydroshrinkage coefficient $\beta$ in the presented model is calculated using MC 2010. The results in Fig. 10b show that the calculated shrinkage strain closely matches the MC 2010 predictions (Fig. 10b) when a value $\beta=1.58 \times 10^{-3}$ is used. Moreover, the relative error of shrinkage strain predictions and the MC 2010 models is around $\pm 5 \%$, which is considered sufficiently accurate. As expected, the results show that the time dependent axial shrinkage strain is significantly affected by the nominal thickness of the box girder section. The shrinkage strain at " $C$ " calculated by the proposed approach is $381 \mu \varepsilon$ at 10,000 days, which is 1.68 times the value at " $\mathrm{A}$ ".

Figure 11 shows the calculated box girder deflection due to shrinkage camber at two points ' $\mathrm{S} 1$ ' and 'S2', which are approximately located at the free end and mid-span of the cantilever girder. As expected, the varying thickness of the web and bottom slab produces significant upward vertical displacements along the cantilever girder. This deflection increases over time up to 11,000 days, when it reaches maximum values of $3.0 \mathrm{~cm}$ and $1.8 \mathrm{~cm}$ at ' $\mathrm{S} 1$ ' and 'S2', respectively. After this peak point, the deflection decreases since the 


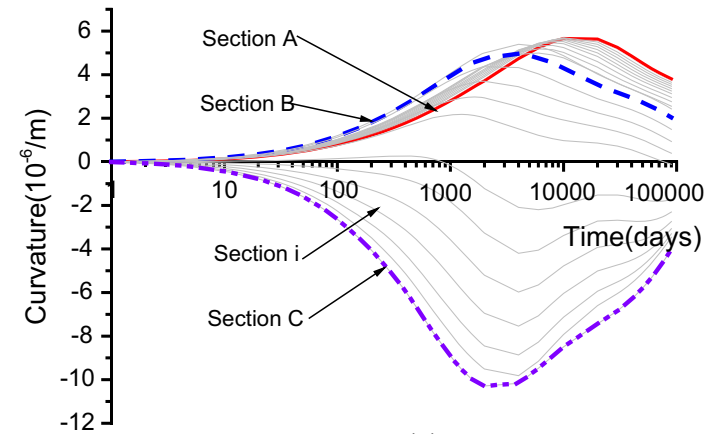

(a)

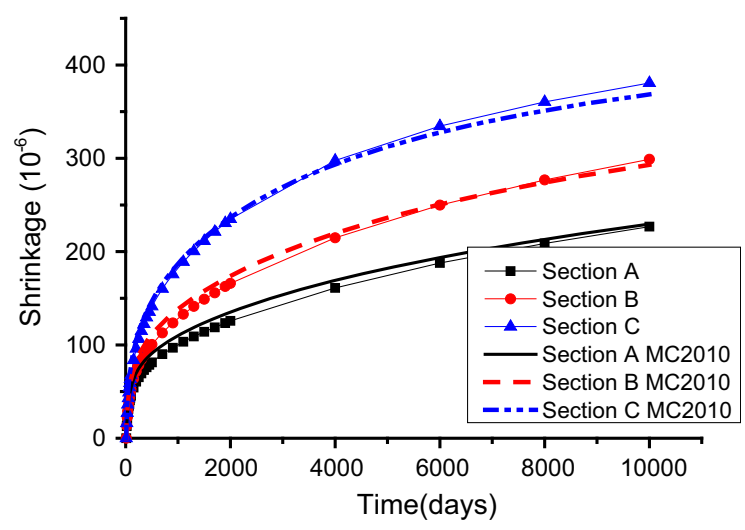

(b)

Fig. 10 a Evolution of shrinkage camber with time and b shrinkage at sections "A", "B" and "C" of Yiju River Bridge. a Shrinkage curvature, b Shrinkage strain

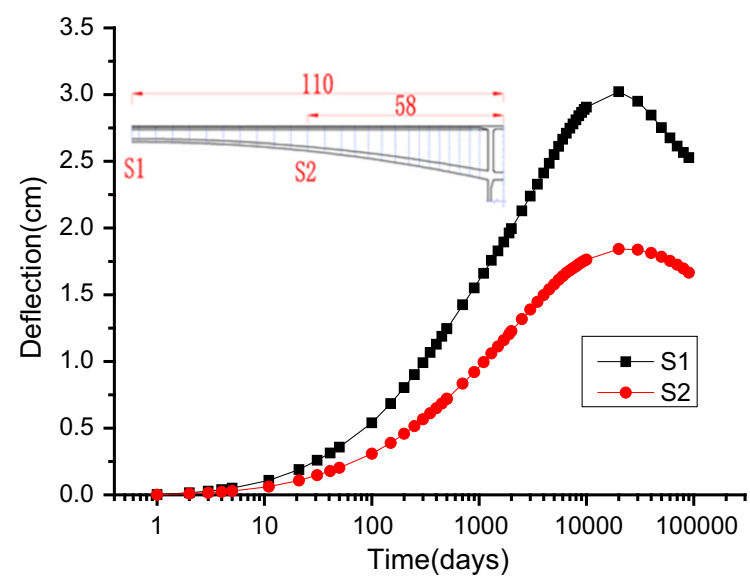

Fig. 11 Calculated deflection of the cantilever girder of Yiju River Bridge majority of internal moisture in the top slab has been consumed by convection, the shrinkage at the top slab developed more slowly than at the bottom slab. According to the design, creep and prestressing losses will produce a $4.3 \mathrm{~cm}$ downward deflection in the bridge after 27 years of service. However, around 70\% of such deflection can be potentially compensated by the shrinkage camber of the box girder section. It should be also noted that the influence of creep was disregarded in the analyses. Accordingly, current research by the authors is investigating the influence of creep on shrinkage-induced deformations, and their findings will be published in a forthcoming paper.

Overall, the results of this study indicate that the long term behaviour of long-span box girder bridges is affected by shrinkage camber, and therefore such additional curvatures need to be included in the analysis and design. Based on the results of this study, it can be concluded that the use of data from simple tests, along with inverse FE analyses implementing the adopted hydro-mechanical FE approach, can be used to simulate the shrinkage behaviour of concrete girders exposed to different ambient conditions. Due to the limited test data used for the calibration of the FE models adopted in this study, future research should focus on the determination of suitable surface factors and hydro-shrinkage coefficient values.

\section{Conclusions}

This article examined experimentally and analytically the effect of different geometries on the development of shrinkage camber in bridge box girders. Small-scale concrete specimens were subjected to different exposure conditions to measure the development of shrinkage. Based on the experimental results, a parametric analysis was performed to obtain the surface factor and the hydro-shrinkage coefficient. The test results were then used to examine analytically the effect of geometry and ambient relative humidity on the development of shrinkage deformation of the specimens using a hydro-mechanical approach. The proposed approach was then verified using the Yiju River Bridge (China) as a case study. Based on the experimental and analytical results presented in this article, the following conclusions are drawn: 
1. Test results from concrete beams with I cross section indicate that axial shortening (due to uniform shrinkage) and shrinkage camber (due to different cross section geometry) occurred simultaneously. The shrinkage camber increased initially up to a peak point, after which it decreased. The results also indicate that the shrinkage camber can recover when the $\mathrm{RH}$ of the testing environment increases.

2. Based on test results and FE inverse analyses, surface factors $f=0.3-0.5 \mathrm{~mm} /$ day and a hydroshrinkage coefficients $\beta=0.0014-0.0015$ were derived for typical concrete mixes used in bridge design/construction in China. The use of these values in a hydro-mechanical approach proved very effective at simulating the experimental shrinkage-induced bending deformations of the I beams subjected to different exposure conditions.

3. Results from parametric FE analyses confirm that section size and ambient humidity are the main factors affecting the development of shrinkage deformations in concrete girders. Moreover, the section size affects both the maximum value of shrinkage camber and the time at which it is achieved. However, only the thickness of the cross section components had a major influence on the response after the maximum camber was achieved.

4. The proposed hydro-mechanical FE approach provides a reasonable estimate of the RH of sections of the Yiju River Bridge. Based on these estimates, it is shown that in the long term (27 years), approximately $70 \%$ of the vertical deflection can be potentially compensated by the shrinkage camber of the box girder section (excluding creep effects).

5. The results of this study confirm that the long term behaviour of long-span box girder bridges is affected by shrinkage camber, and therefore such additional curvatures need to be included during initial analysis and subsequent assessment.

Acknowledgements The first authors thankfully acknowledge the financial support of the Research Fund for the Doctoral Program of Higher Education of China (Grant No. 20125522120001).

\section{Compliance with ethical standards}

Conflict of interest The authors declare that there is no financial or other conflict of interest relevant to the subject of this article.
Open Access This article is distributed under the terms of the Creative Commons Attribution 4.0 International License (http:// creativecommons.org/licenses/by/4.0/), which permits unrestricted use, distribution, and reproduction in any medium, provided you give appropriate credit to the original author(s) and the source, provide a link to the Creative Commons license, and indicate if changes were made.

\section{References}

1. Gribniak V, Kaklauskas G, Kliukas R, Jakubovskis R (2013) Shrinkage effect on short-term deformation behavior of reinforced concrete-when it should not be neglected. Mater Des 51:1060-1070. doi:10.1016/j.matdes.2013.05. 028

2. Bažant ZP, Yu Q, Li GH (2012) Excessive long-time deflections of prestressed box girders. I: record-span bridge in Palau and other paradigms. J Struct Eng 138(6):676-689. doi:10.1061/(asce)st.1943-541x

3. Bažant ZP, Yu Q, Li GH (2012) Excessive long-time deflections of prestressed box girders. II: numerical analysis and lessons learned. J Struct Eng 138(6):687-698. doi:10. $1061 /$ (asce)st.1943-541x

4. ACI (2010) ACI 231R-10: report on early-age cracking: causes, measurement, and mitigation. American Concrete Institute, Farmington Hills

5. ACI (2008) ACI 209.2R-08: guide for modeling and calculating shrinkage and creep in hardened concrete. American Concrete Institute, Farmington Hills

6. CEB (2013) Fib model code for concrete structures 2010. Wilhelm Ernst \& Sohn, Berlin

7. Bažant ZP, Donmez A (2015) Extrapolation of short-time drying shrinkage tests based on measured diffusion size effect: concept and reality. Mater Struct 14:1-10. doi:10. 1617/s11527-014-0507-0

8. Křístek V, Bažant ZP, Zich M, Kohoutková A (2006) Box girder bridge deflections. ACI Concr Int 28(1):55-63

9. Malm R, Sundquist H (2010) Time-dependent analyses of segmentally constructed balanced cantilever bridges. Eng Struct 32(4):1038-1045. doi:10.1016/j.engstruct.2009.12. 030

10. Bakhshi M, Mobasher B, Soranakom C (2012) Moisture loss characteristics of cement-based materials under earlyage drying and shrinkage conditions. Constr Build Mater 30:413-425. doi:10.1016/j.conbuildmat.2011.11.015

11. Kim JK, Lee CS (1998) Prediction of differential drying shrinkage in concrete. Cem Concr Res 28(7):985-994

12. Orta Cortes, JL (2009) Restrained shrinkage in bridge decks with concrete overlays, Ph.D. thesis, University of Western Ontario, p 218

13. Li Z, Perez Lara MA, Bolander JE (2006) Restraining effects of fibers during non-uniform drying of cement composites. Cem Concr Res 36(9):1643-1652. doi:10.1016/ j.cemconres.2006.04.001

14. Li H, Liu J, Wang Y, Yao T, Tian Q, Li S (2015) Deformation and cracking modeling for early-age sidewall concrete based on the multi-field coupling mechanism. Constr Build Mater 88:84-93. doi:10.1016/j.conbuildmat.2015.03. 005 
15. Knoppik-Wróbel A, Klemczak B (2015) Degree of restraint concept in analysis of early-age stresses in concrete walls. Eng Struct 102:369-386. doi:10.1016/j.engstruct.2015.08. 025

16. Briffaut M, Benboudjema F, Torrenti JM, Nahas G (2011) Numerical analysis of the thermal active restrained shrinkage ring test to study the early age behavior of massive concrete structures. Eng Struct 33(4):1390-1401. doi:10. 1016/j.engstruct.2010.12.044

17. Kwak HG, Ha SJ, Kim JK (2006) Non-structural cracking in RC walls. Cem Concr Res 36(4):749-760. doi:10.1016/j. cemconres.2005.12.001

18. CEB (1990) CEB-FIP model code for concrete structures. Lausanne, Switzerland

19. Jafarifar N, Pilakoutas K, Bennett $T$ (2014) Moisture transport and drying shrinkage properties of steel-fibre-reinforced-concrete. Constr Build Mater 73:41-50. doi:10. 1016/j.conbuildmat.2014.09.039

20. West RP, Holmes N (2005) Predicting moisture movement during the drying of concrete floors using finite elements. Constr Build Mater 19(9):674-681. doi:10.1016/j. conbuildmat.2005.02.014

21. Bernard O, Bruhwiler E (2003) The effect of reinforcement in the new layer on hygral cracking in hybrid structural elements. Mater Struct 36:118-126

22. Sadouki H, Van Mier JGM (1997) Simulation of hygral crack growth in concrete repair systems. Mater Struct 30:518-526
23. Kim JK, Lee CS (1999) Moisture diffusion of concrete considering self-desiccation at early ages. Cem Concr Res 29:1921-1927

24. Bathe KJ (1996) Finite element procedures, 1st edn. Prentice-Hall, Upper Saddle River

25. Zhu BF (2014) Thermal stresses and temperature control of mass concrete, 1st edn. Butterworth-Heinemann, Waltham

26. ARaD Inc (2001) ADINA - theory and modeling guide. Report 01-7, Watertown, MA

27. China Ministry of Transport (2004) Code for design of highway reinforced concrete and prestressed concrete bridges and culverts-JTG D62-2004. Beijing, China (in Chinese)

28. Kaklauskas G, Gribniak V, Bacinskas D, Vainiunas P (2009) Shrinkage influence on tension stiffening in concrete members. Eng Struct 31(6):1305-1312. doi:10.1016/j. engstruct.2008.10.007

29. Yoo SW, Koh KT, Kwon SJ, Park SG (2013) Analysis technique for flexural behavior in $\mathrm{RC}$ beam considering autogenous shrinkage effect. Constr Build Mater 47:560-568. doi:10.1016/j.conbuildmat.2013.05.061

30. Vasiliev V, Morozov EV (2013) Advanced mechanics of composite materials and structural elements, 3rd edn. Elsevier, Waltham

31. Moore H (2014) MATLAB for engineers, 4th edn. Pearson, Upper Saddle River 